\title{
The Enterprise Resource Planning (ERP) System and Spatial Information Integration in Tourism Industry---- Mount Emei for Example
}

\author{
YAN Lei $^{1}$, WANG Jing-bo ${ }^{2}$, MA Yuan-an ${ }^{2}$, DOU Jing ${ }^{1}$ \\ ${ }^{1}$ Peking University Beijing 100871, P.R. China \\ lyanepku.edu.cn, doujing@263. net \\ ${ }^{2}$ Governmental Committee of Emei Tour Sites, Emei City, Sichuan 614200, P.R. China \\ jbwang 747 @yahu. com
}

\begin{abstract}
An integrated information system (ERP system) of tourism industry is proposed in this paper for the management of the planning of Mt. Emei and the relative industries. The authors also demonstrate the advantages of ERP solution, including its construction and functional realization in detail. The fusion of much spatial information in the ERP system is discussed and a spatial integrated information scheme is proposed.
\end{abstract}

\section{Overview}

Tourism is a service industry. As to the development of computer technology and Tourism in these years, cyber-systems are used to manage the tourism and its corporations. Due to tourism as an opening, complicated and huge system ${ }^{[1]}$, the research about it should covered with synthetical and integrated methods. Also GIS (Geography Information System) could be used in the inosculation of spatial information and other ones ${ }^{[2][3]}$.

The method of ERP (Enterprise Resource Planning) system to manage and research the tourism system is proposed ---- Mt. Emei for example. The artifices of GIS are utilized in the integration of spatial information. Tour sites of Mt. Emei are managed by the Governmental Committee, including hotels, tourism agencies, etc.

\section{The Application of ERP in Tourism Industry}

ERP is an advanced operation system in industry ${ }^{[4]}$. It divides an enterprise into several subsystems. These subsystems are interdependent and cooperated each other. The workflow of the corporation is looked upon a chain of closely supplied links. Not only the manufacturing corporation but also the service one could be managed by the ERP system. 
As to the tourism, ERP could be used to manage every taches of the traveling service chain, including management of finance, human resource, service, maintenance, projects, stocking, investment, risk, decision-making, payoff analyzing, region planning, region business, and intelligent traffic. The mainframe of Mt. Emei Information System (ERP) is shown in Fig.1.

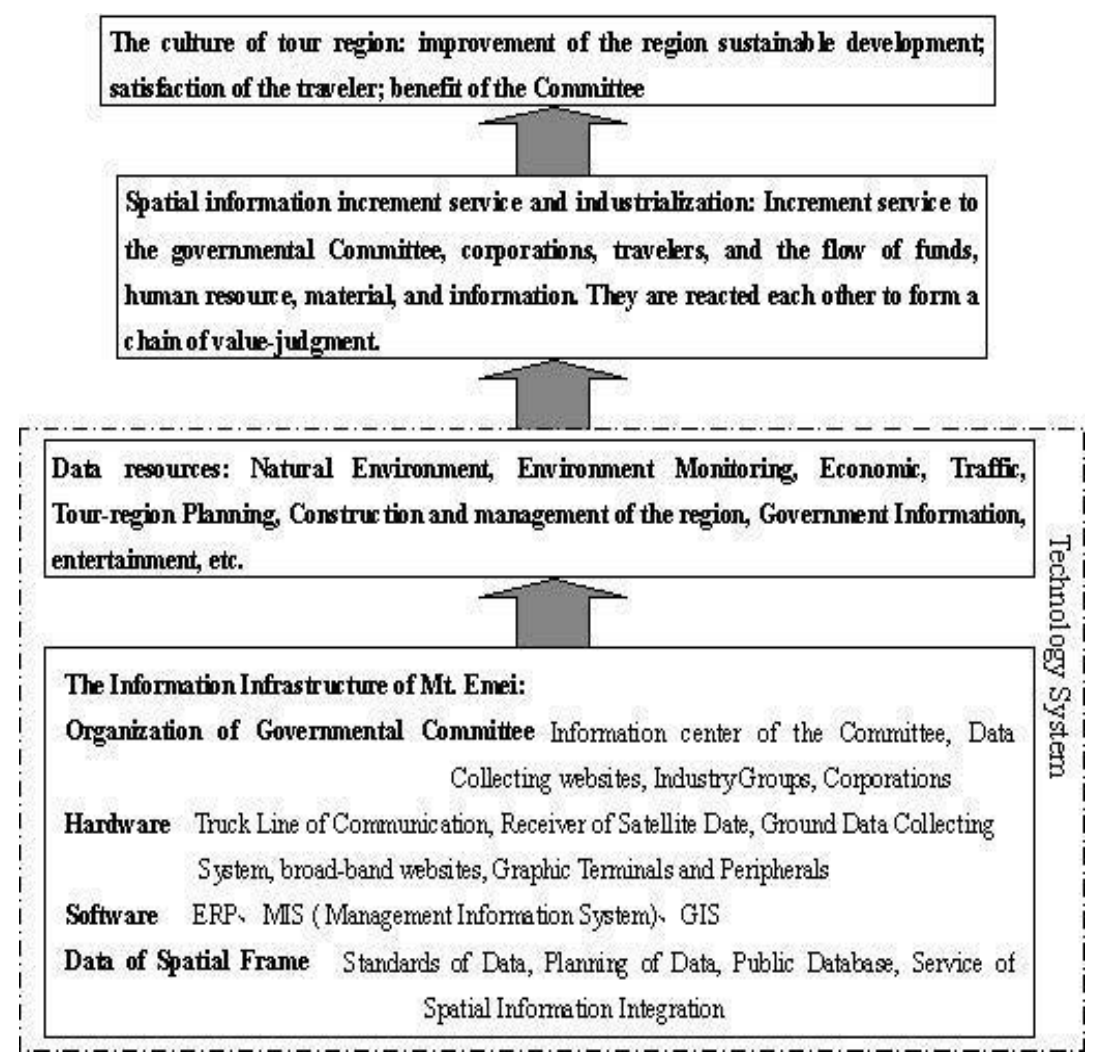

Fig. 1. The Concept Frame of Mt. Emei Information System (ERP)

\section{The General Frame of Integrated Information System (ERP) on Mount Emei}

The general frame is composed of a system for data obtaining and updating, database, data processing, and information announcement.

For the ERP, the multimedia database is its base and the function modules are its structure. And the laters can be divided into the application of government, corporation and business according to the attribute of the users. The general frame of 
the system is showing in Fig.2. Here RS means Remote Sensing, GPS does Global Positioning System, PDA does Personal Digital Assistant.

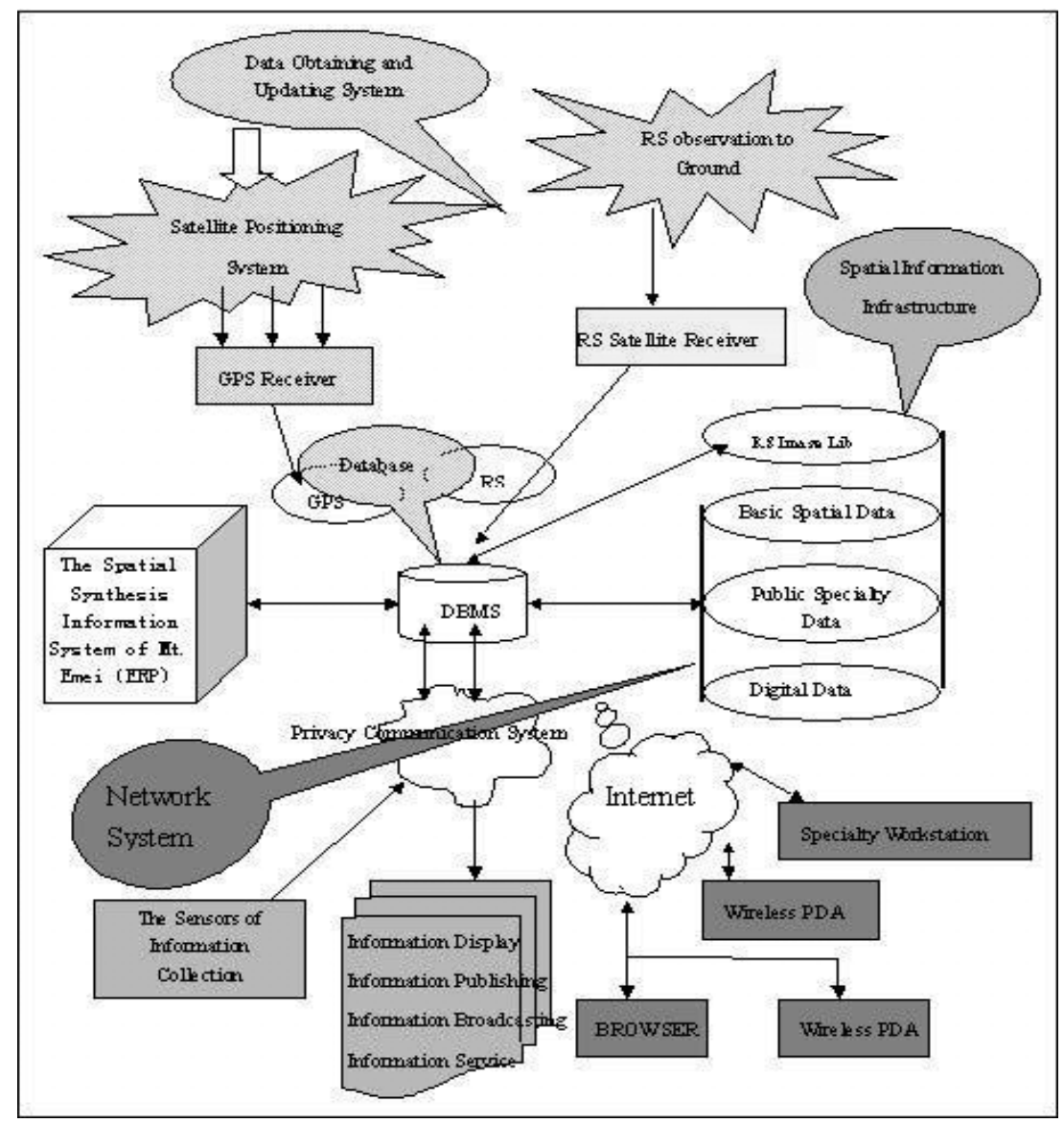

Fig. 2. The general structure of Synthesis Information System on Mt. Emei 


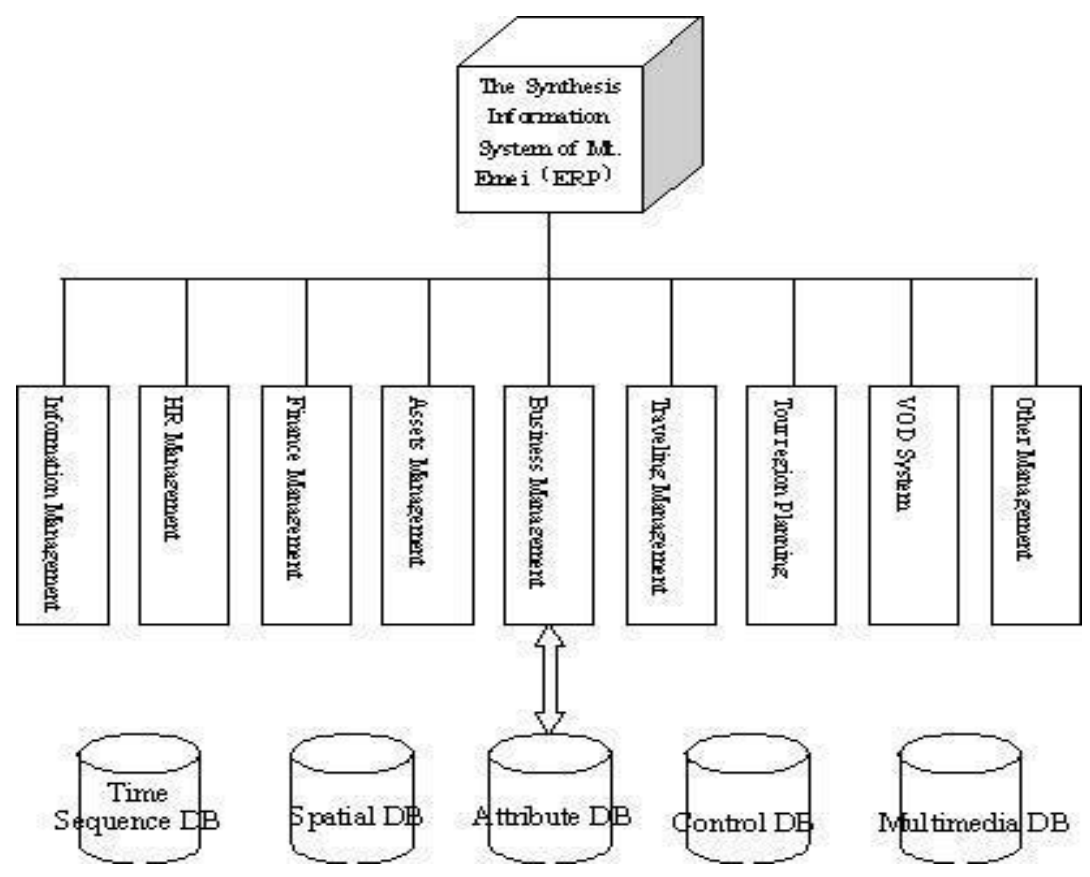

Fig. 3. The Organization Frame of Synthesis Information System of Mt. Emei

\section{System Functions of Synthesis Information System(ERP) on Mount Emei}

The organization frame of Synthesis Information System (ERP) of Mt. Emei is shown in Fig.3. Here VOD means Video-On-Demand; HR does Human Resource; DB does Date-Base.

\section{Information Management Module of Public Data}

The maintenance and management of basic data is provided in this module, including the materials about maps, departments, projects, personals, finance, etc. All basic data can be introduced into other modules.

The system setting and maintenance are also provided, including the function modules about the setting of system information and database, application component setup, re-organization for entertainment module, user or computer management, etc.

\section{The Module of Human Resource Management}


Person is the most important composition of the corporation. The management of human resource helps us to improve the service quality and satisfy customers.

The module of HR management benefits the decision in HR planning. First, simulative comparison and operational analysis are performed to create many schemes about human and organization structure. Then, direct evaluation with graphics is given out to help the administrator to make the final decision. Third, this module should be used to decide a man's post-and-rank module, including post requirement, promotion path and training plan. Fourth, the module should be used to have a series of training suggestions based on the employee's qualification and condition, to give out cost analysis in past, present and future. Therefore, this module also can be used for training management and diathesis evaluation.

Moreover, this module should be used to provide functions like salary audit, manhour management and allowance audit for business trip, etc.

\section{Finance Management Module}

A clear finance management is very important for a corporation. The finance module in ERP is different with other common finance software. As a part of the system, this module has interface with other ones in the system, and can be integrated with other modules. The module can automatically generate whole account and accountant report forms according to the business information and stock activities. The finance module in ERP consists of two parts: the accountant audit and finance management. The former functionality is to record, audit and analyze the capital flow and results in the corporation activities. The later one is to analyze the former's data and give out corresponding prediction, management and control. After the ERP works, the budget of every department is included in the capital management of the corporation. Administrator can check the capital, selling costs, incomed or outgone money. The ERP can also be integrated with other finance software and set the standardization of the finance management.

\section{Asset Management Module}

As an integrated information system, ERP can also be used for asset management. This column includes purchase, usage and maintenance of the facilities. For example, as vital assets, vehicles can be analyzed for its transportation power, route and consume. And we can know vehicles' condition and make sure the tourist's security.

\section{Business Management Module}

The ERP will integrate most of the sales' business in the corporation, and realize market sales, finance prediction, dispatch of the product power and its resource. It is the main assistant platform for sale management and decision in the corporation. The ERP will help the corporation to streamline the flow of order-stock- (production)-sale, 
to refine the finance management, to realize the resource share for the material, capital and information flows.

\section{$2 \quad 26$ Tourism Management Module}

As a tourism corporation, its management is very important. The management module includes all the information about the tourism services. This information comes from the different department of Mt. Emei. The module also consists of many decisionmaking and analysis tools. These tools will help the tour manager to provide comprehensive, detail and thoughtful services to customers, develop the more and better planning, and to improve the tourist's services for his consume activities. This module is related to tourists and the business department of Mt. Emei.

The module functions of tourism management include:

(1) Ticket incoming management: strict ticket management to improve the incoming of the ticket sales and to facilitate tourist management.

(2) Support to remote users: Direct illustration of the panorama of Mt. Emei through integration of video, sound, 3D and text.

(3) Tourism market analysis: Information query for users in menu or map form.

\section{Planning Management Module on Mount Emei}

The incorporation of GIS into ERP will help the planning stuff of Mt. Emei get different materials, productivity, the basis for the leaders to understand, grasp, analyze present situation of Mt. Emei and to have decision-making.

\section{$2 \quad 28$ VOD Video On Demand System}

The VOD is based on Open Video system, which is a browser-server module. It has a multi-layer structure, and consists of video server, WWW server and database server. VOD system can be provided to the tourists with VOD services.

\section{Integration of Tourism Management and Spatial Compositive Information}

The ERP of Mt. Emei is a highly integrated system, which involves many domains. Shown in Figure 4, the information project for the governmental committee of Mt. Emei is based on this system. 


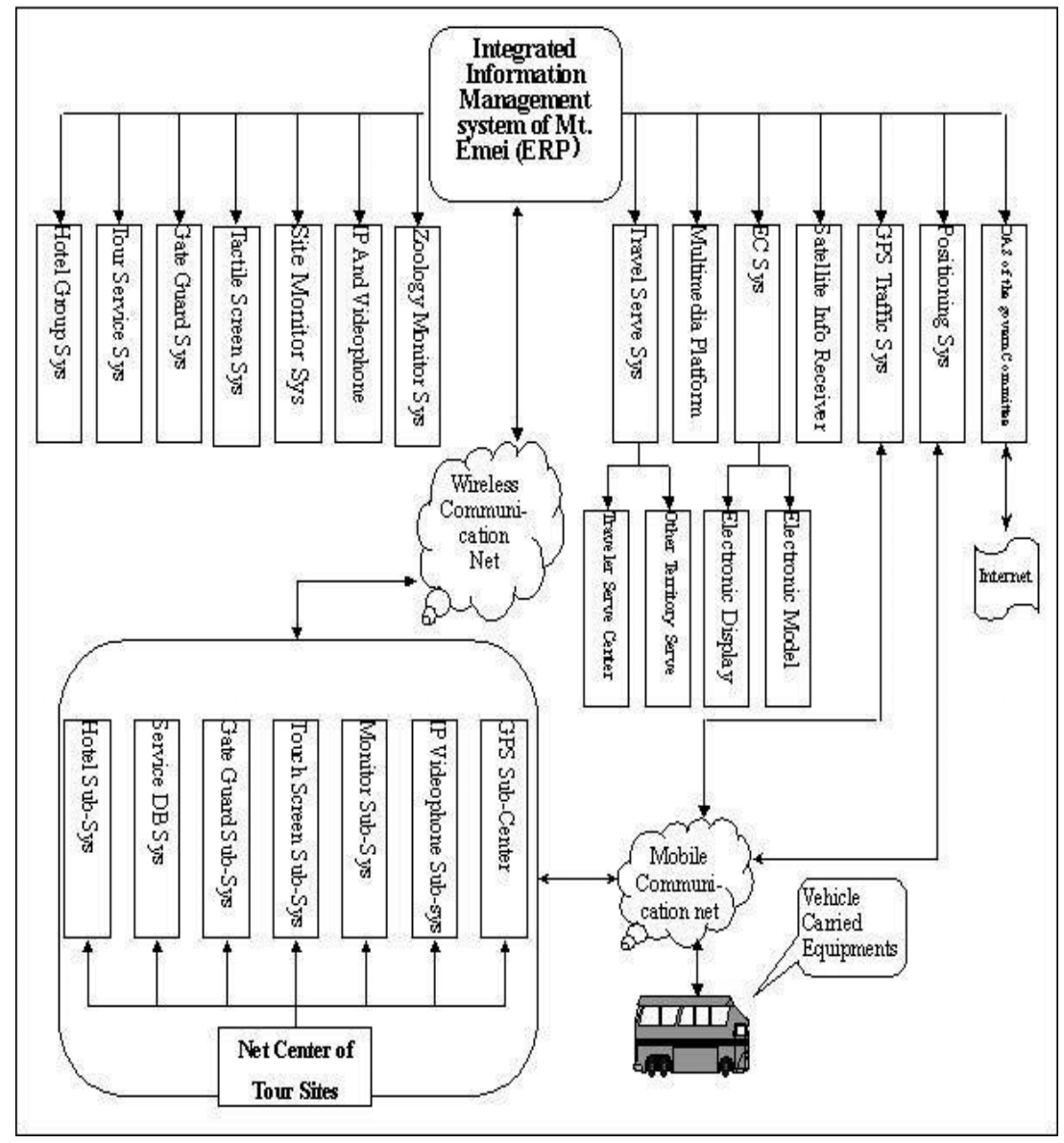

Fig. 4. System Structure of ERP

Here EC means Electronic Commercial, OAS does Office Automation System.

Many models in the system will produce all kinds of spatial information:

(1) Vehicle Management System: Control of the vehicle operation and schedules by GPS technology to ensure tourist security.

(2) Surveillant System: large scale of surveillance for tour spots and hotels.

(3) Tiros Receiver System: reception of Tiros signals to give an alarm for large scale of calamity, such as flood, fire, earthquake and so on.

(4) Positioning and Searching System: Definition of positioning and searching services by wireless technology to ensure the tourists security.

(5) Entironment Monitor System: Surveil lance of the entironment to support the sustainable development of Mt. Emei. 
All above systems should be integrated, and can be efficiently merged with each other via GIS platform in the ERP system. It will benefit information interchange in the corporation and analysis/decision support of information management. Furthermore, this kind of spatial integrated information can be intuitively reflected in other systems.

\section{Some Information Sub-system Realization}

All the information system is very large and complex. Its realization is divided into five stages. Stage one is the informatics accidence of tourism service; Stage two is the governmental monitor and upgrade of the tourism brand; Stage three is the construction of technology platform of tourism service; Stage four is the integration service of tour information; Stage five is general information platform of service. Currently, Stage one and two have been finished. The main functional module/subsystem includes:

(1) Electrical sand table: Present Mt. Emei in the microform by high technologies like sound, light and electronic to the tourists.

(2) Tactile screen: Spread the touch screen systems throughout Mt. Emei; propagate all the tour spots in the form of multimedia.

(3) Management system of the Governmental Committee: Manage all daily works of the governmental committee of Mt. Emei.

(4) Tourist center: As a comprehensive and integrated service system, provide the tourists with query, reference, simulation experience, shopping service and so on.

(5) Scatter tourist service center: Provide scatter tourist with an easy, comfort and personalized tourism service.

(6) Emei online website: Provide tourist services like tour sites, cultural, tour path introduction, as well as other facilities.

Generally, when all the planed modules are finished, they will be interacted each other on the ERP system. At the same time, the excellent scalability, interface design of the ERP system and the component based on software development will ensure the constant upgrade of the overall system and the improvement of the function modules.

\section{Conclusions}

Due to the uncertain factor for service industry, tourism system is a very complex huge system. An ERP system for the tour service industry is proposed in this paper for tourism planning and the management of Tourism Corporation. The system integrates much spatial information by the GIS platform, provides scientific foundation and reduces uncertainties for decision and planning. Some realized 
Subsystems have worked well and have been proven that the general designs of the authors are successful and efficient.

\section{References}

1. S.L.Zhang, Z.J.Zou, Tourism Planning Synthesis Integrated Methodology Dealing with the Open, Complicated and Large System, Human Geography, Vol.16, No.1, Feb. 2001, P11 15

2. C.Q.Li, etc, Research based on GIS System to the National Tourism Beauty Spots. Science of Surveying and Mapping, Vol 26 No.2 Jun., 2001, P35 38

3. L.Wu, L.Yu, J.Zhang, X.J.Ma, S.Y.Wei, Y.Tian, 2001, Geography Information System Principle, Methodology and Application, Science Press

4. L.Yan, 1998, Base of sustainable development System and Structure Control on Resource, Environment \& Ecology, Huaxia Publishing House 